\title{
Highly Selective Intercalation of Primary Amines in a Continuous Layer Ag Coordination Network
}

Leslie J. May, George K. H. Shimizu*

Department of Chemistry, University of Calgary

2500 University Drive NW, Calgary, Alberta. Fax: 1403289 9488; Tel: 1403220

5347; E-mail: gshimizu@ ucalgary.ca

\section{Experimental:}

\section{Synthesis of 4-Pyridinesulfonic acid $(L)$}

To (4-pyridyl)pyridinium chloride hydrochloride ( $19 \mathrm{~g}, 0.083$ moles) dissolved in 100 $\mathrm{mL}$ of water, sodium sulfite heptahydrate (31.5 g, 0.25 moles) was slowly added. Once the evolution of sulfur dioxide ceased, the mixture was refluxed for $24 \mathrm{hrs.} \mathrm{After} \mathrm{cooling}$ to room temperature, the reaction was transferred to a $1000 \mathrm{~mL}$ round-bottom flask, diluted with $400 \mathrm{~mL}$ of water and six scoops of charcoal were added. The reaction was then refluxed for $3 \mathrm{hr}$, allowed to cool to room temperature and left to stir overnight. The charcoal was then removed by filtration, and the solvent of the filtrate removed in vacuo. The crude solid was recrystallized with $90 \%$ ethanol to give 4-pyridine sulfonate, sodium salt. To obtain the sulfonic acid derivative, the sodium salt was converted using cationic exchange resin. Overall yield; $35 \%$. EA; anal. calcd for $\mathrm{C}_{5} \mathrm{H}_{5} \mathrm{NSO}_{3}(159.16 \mathrm{~g} / \mathrm{mol}), \mathrm{C}$ 37.73, H 3.17, N 8.80; found C 37.70, H 3.16, N 8.69. IR (KBr pellet); $v\left(\mathrm{~cm}^{-1}\right) 3120(\mathrm{w})$, 3069(w), 3003(w), 2790(m), 1629(s), 1612(s), 1507(s), 1483(s), 1332(m), 1245(s), 1189(s), 1128(s), 1085(s), 1026(s), 998(s), 929(m), 824(s), 808(s), 735(s), 716(s), 667(m), 641(m), 611(s), 560(s), 546(s), 487(w). Solution ${ }^{1} \mathrm{H}$ NMR (200 MHz, $\left.\mathrm{D}_{2} \mathrm{O}\right)$; $\delta(\mathrm{ppm}) 8.79(\mathrm{~d}, 2 \mathrm{H}), 8.19(\mathrm{~d}, 2 \mathrm{H}) .{ }^{13} \mathrm{C}$ SSNMR $(300 \mathrm{MHz}$, spun at $4.5 \mathrm{kHz}) ; \delta(\mathrm{ppm})$ $159.73,142.89,144.79,126.72$.

Synthesis of Silver(4-pyridinesulfonate) - (1)

Synthesis of Silver(4-pyridinesulfonate) - (1)

In a $50 \mathrm{~mL}$ round-bottomed flask silver carbonate ( $0.275 \mathrm{~g}, 1 \mathrm{mmole})$, 4-pyridinesulfonic acid $(0.317 \mathrm{~g}, 2 \mathrm{mmole})$ and $25 \mathrm{~mL}$ of methanol were combined. The green colored mixture was sonicated for 30 minutes, at which time the reaction became grey accompanied by release of small amounts of gas $\left(\mathrm{CO}_{2}\right)$. The resulting solid was collected and dried. Yield; 90\% EA; anal. Calcd for $\mathrm{AgC}_{5} \mathrm{H}_{4} \mathrm{NSO}_{3}(266.0203 \mathrm{~g} / \mathrm{mol}), \mathrm{C} 22.57, \mathrm{H}$ 1.52, N 5.27; found C 22.13, H 1.17, N 5.12. IR (KBr pellet); $v\left(\mathrm{~cm}^{-1}\right) 3108(\mathrm{w}), 3090(\mathrm{w})$, 3074(w), 3036(w), 1596(s), 1411(s), 1381(m), 1208(s), 1187(s), 1133(s), 1031(s), 1015(m), 837(m), 742(m), 613(s), 567(m), 546(w). ${ }^{1} \mathrm{H}$ NMR (200 MHz, $\left.\mathrm{D}_{2} \mathrm{O}\right) ; \delta(\mathrm{ppm})$ $8.55(\mathrm{~d}, 2 \mathrm{H}), 7.67(\mathrm{~d}, 2 \mathrm{H}) .{ }^{13} \mathrm{C}$ SSNMR $(300 \mathrm{MHz}$, spun at $4.5 \mathrm{kHz}) ; \delta(\mathrm{ppm}) 154.84$, 152.62, 123.93, 120.45. DSC/TGA; $\left(273{ }^{\circ} \mathrm{C}\right.$, endo; $305^{\circ} \mathrm{C}$, endo), $330-391{ }^{\circ} \mathrm{C}\left(364^{\circ} \mathrm{C}\right.$, endo; $385^{\circ} \mathrm{C}$, endo). PXRD (1.54056 ̊̊); $d$-spacing $(\AA) / 2 \operatorname{theta}\left({ }^{\circ}\right)$ (h k l) 8.0202/11.023 (0 0 1), 7.5319/11.740 (2 0 0), 5.6557/15.655 (-2 0 1), 5.3387/16.591 (2 0 1), 5.0913/17.404 


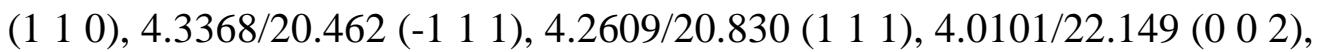
3.7660/23.605 (4 0 0), 3.6802/24.163 (3 1 0), 3.6276/24.519 (-2 0 2), 3.4578/25.743 (2 0 2), 3.3999/26.190 (-3 1 1), 3.2925/27.060 (3 11 1), 3.1806/28.031 (-1 1 2), 3.1208/28.579 (1 1 2), 2.8279/31.613 (-4 0 2), 2.7705/32.286 (-3 1 2), 2.7048/33.092 (0 2 0), 2.6694/33.544 (4 0 2), 2.6560/33.717 (3 1 2), 2.6321/34.033 (5 10 ), 2.5662/34.930 (-2 0 3), 2.5456/35.226 (2 20 ), 2.5391/35.320 (-5 1 1), 2.5106/35.734 (6 0 0), 2.4643/36.429 (5 1 1), 2.4401/36.803 (-2 2 1), 2.4128/37.235 (2 2 1), 2.3862/37.666 (-1 13 ), 2.3481/38.299 (1 13 3), 2.2424/40.181 (0 2 2), 2.1969/41.051 (4 2 0), 2.1855/41.275 (-6 0 2), 2.1512/41.963 (5 12 2), 2.1304/42.392 (2 2 2), 2.1009/43.018 (4 2 1), 2.0748/43.586 (6 0 2), 2.0050/45.184 (0 0 4), 1.996/43.315 (7 10 ), 1.9660/46.133 (-2 0 4), 1.9546/46.417 (-4 2 2), 1.9103/47.559 (2 0 4), 1.9014/47.797 (0 2 3), 1.8781/48.426 (-1 14$)$, $1.8618 / 48.879$ (-2 2 3), 1.8401/49.493 (6 2 0)1.8291/49.812 (-7 1 2), 1.8128/50.260 (-4 0 4), 1.7904/50.963 (1 3 0), 1.7523/52.154 (7 1 2), 1.7500/52.29 (-1 3 1), 1.7449/52.394 (1 3 1), $1.7436 / 52.434$ (-8 0 2), 1.7261/53.008 (-4 2 3), 1.6999/53.889 (-6 2 2), 1.6700/54.937 (4 2 3), 1.6538/55.519 (3 3 1), 1.6391/56.062 (-1 3 2), 1.6352/56.205 (-5 1 4), 1.6128/57.058 (-6 04$), 1.5990 / 57.597$ (9 1 0), 1.5903/57.942 (-2 24$)$.

\section{Intercalation Experiments}

Amine guest (1 mmol) dissolved in diethyl ether was added to an equimolar amount of the layered host (1) suspended in diethyl ether. The heterogeneous mixture was stirred for $6 \mathrm{hrs}$, at which time the ether was removed by filtration. No uptake of diethyl ether by the host was observed in either the presence or absence of amine guests (as determined by PXRD and TGA/DSC).

\section{Competition Experiments}

Equimolar amounts $(2 \mathrm{mmol})$ of a primary, secondary and tertiary amine were combined with tetradecane $(5 \mathrm{~mL})$. This mixture was then added to the solid host and stirred at room temperature. Aliquots $(20 \mu \mathrm{L})$ were removed from the mixture at various time intervals $(0,15,30,60$ and $180 \mathrm{~min})$ and subjected to GC-MS analysis. 
Figures illustrating selective uptake of different amines by host 1. Note, GC experiments illustrating exclusion of potential guests, although performed, are not depicted as the figures themselves show nothing.

Figure S1. GC analyses over time showing the uptake of $\boldsymbol{n}$-butylamine $(\mathrm{t} \approx \mathbf{2} \mathrm{min})$ in the presence of an equimolar amount of $\mathrm{di}(n$-butyl)amine $(t \approx 14 \mathrm{~min})$ and tributylamine $(t \approx 30 \mathrm{~min})$ by layered host 1 .
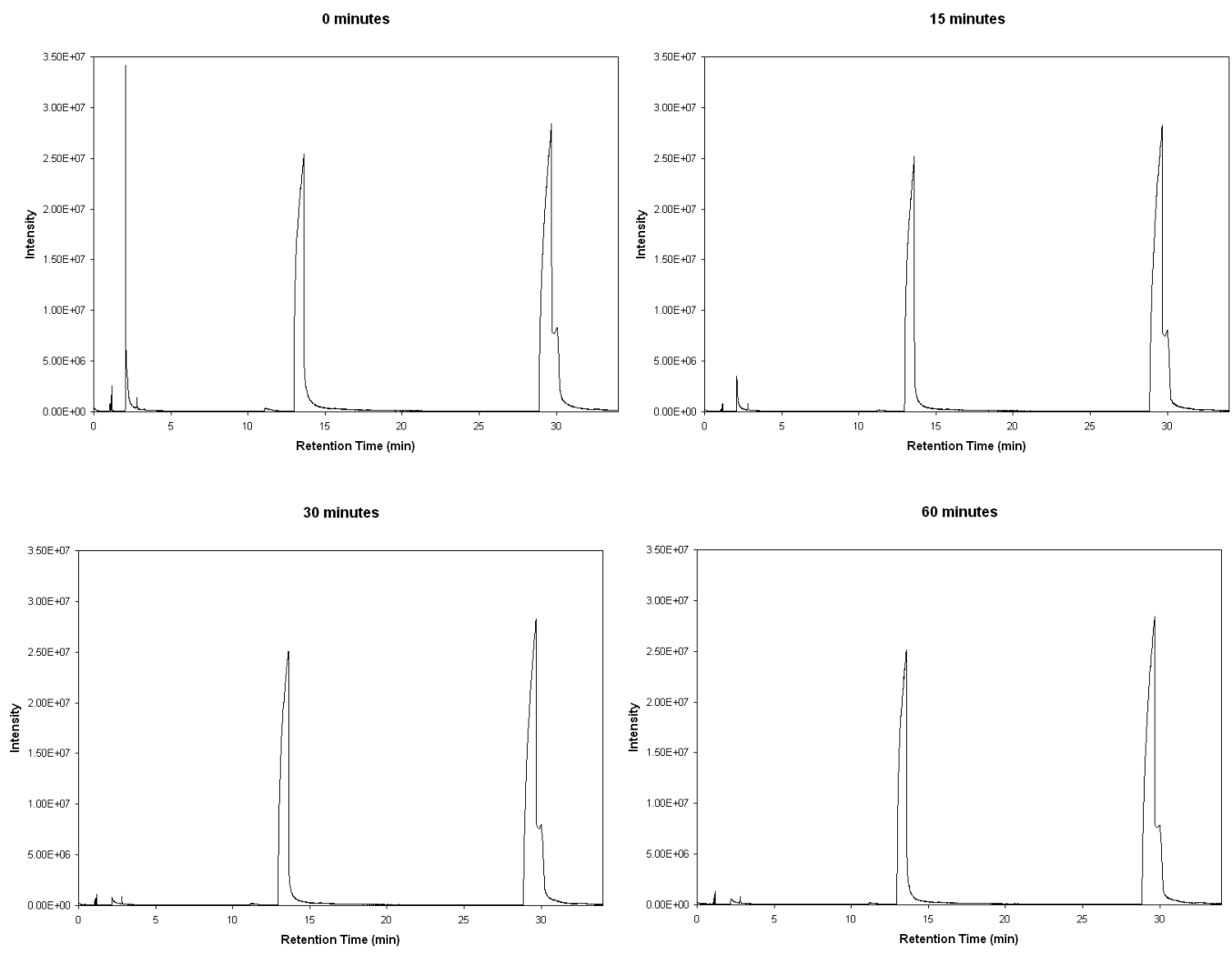
Figure S2. GC analyses over time showing the much slower uptake of di(nbutyl)amine $(t \approx 14 \mathrm{~min})$ in the presence of an equimolar amount of tributylamine ( $t$ $\approx 30$ min) by layered host 1 .
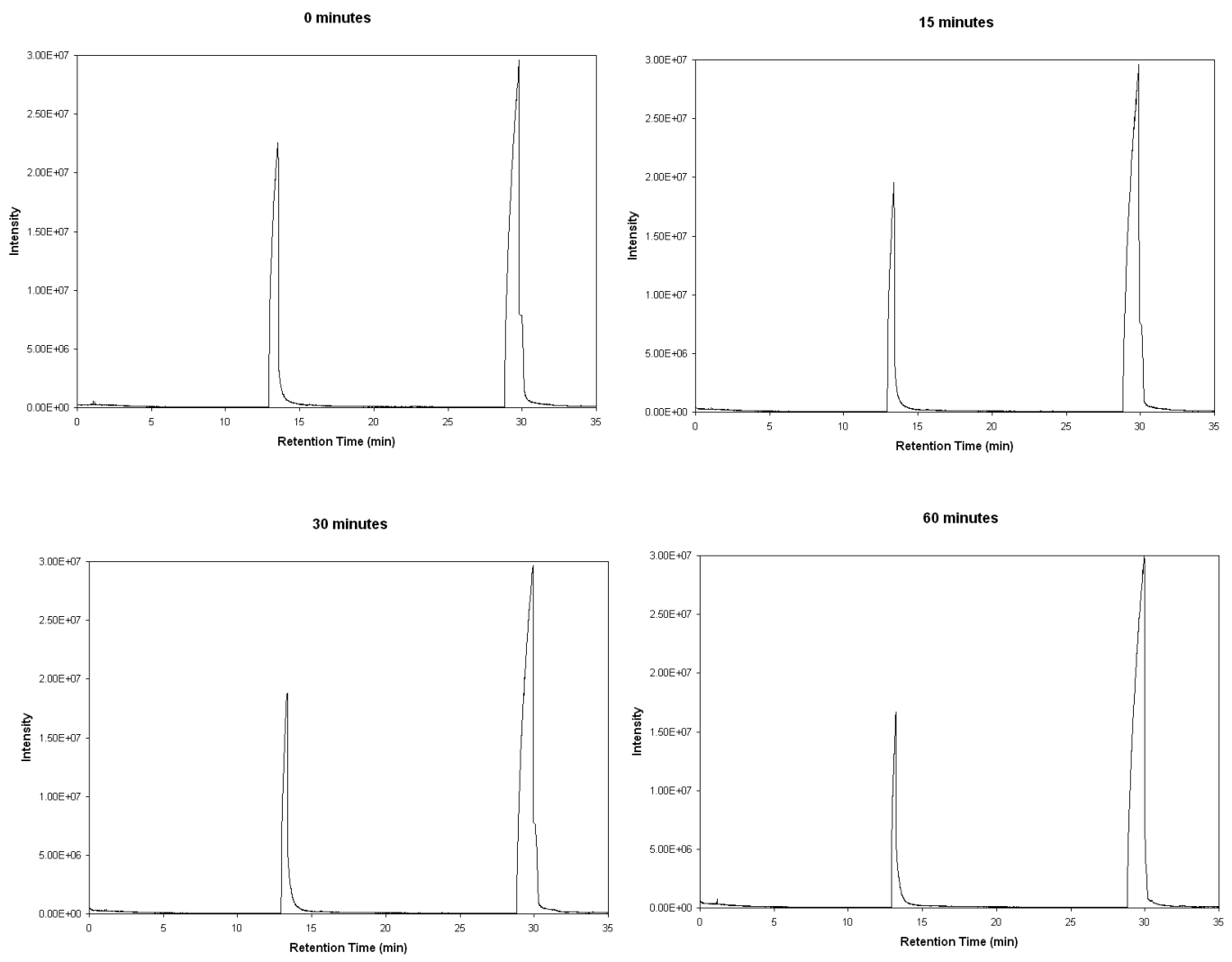
Figure S3. GC analyses over time showing the selective uptake of $n$-butylamine $(t \approx$ $2.1 \mathrm{~min})$ in the presence of an equimolar amount of $n$-butanol $(t \approx 2.9 \mathrm{~min})$ by layered host 1.

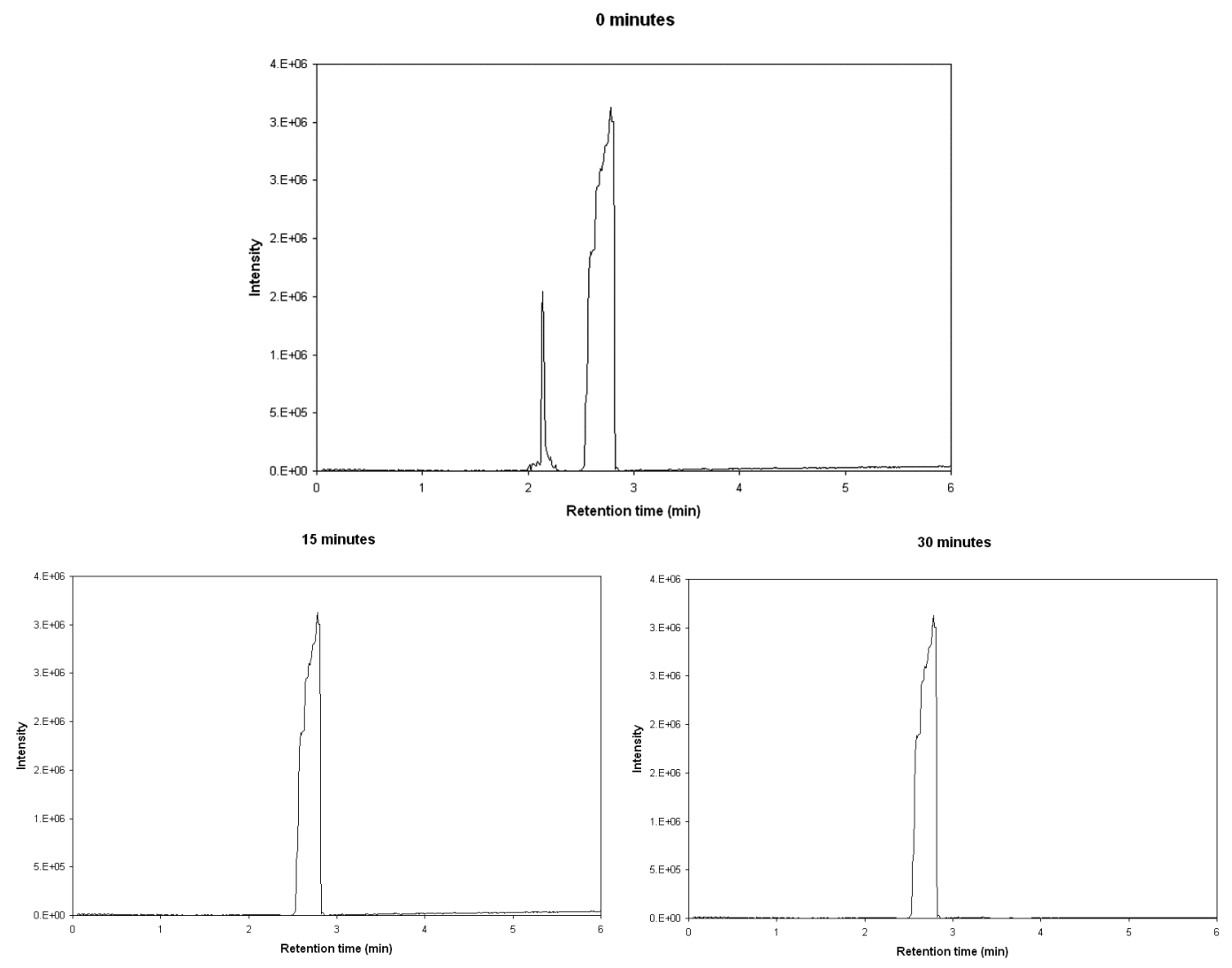

